\title{
A justiça informal em linha de montagem Estudo de caso da dinâmica de atuação do JECrim de Belo Horizonte
}

\author{
Informal Justice on the assembly line
}

A case study of the performance dynamics of the JECrim in Belo Horizonte

\author{
Eduardo Cerqueira Batitucci \\ Marcus Vinícius Gonçalves da Cruz \\ Andréia dos Santos \\ Ludmila Mendonça Lopes Ribeiro \\ Leticia Godinho de Souza*
}

\begin{abstract}
Resumo: Neste artigo analisamos a inovação proporcionada pelo Juizado Especial Criminal no interior do Sistema de Justiça Criminal brasileiro, bem como seu efetivo funcionamento - suas práticas e procedimentos - e as principais características do seu fluxo processual, a partir dos achados da pesquisas sobre o JECrim do município de Belo Horizonte/MG. O artigo consolida resultados de um conjunto de pesquisas tanto qualitativas quanto quantitativas sobre esta instância processual, onde se buscou desde a análise de atitudes, valores e crenças de seus membros, até um levantamento sistemático dos tempos do fluxo dos processos julgados. As conclusões apontam para o questionamento do JECrim/BH como uma instância relevante para a solução de conflitos em Belo Horizonte, em virtude do longo tempo médio encontrado para a solução processual de um caso típico, em virtude da forte burocratização implementada pelo juizado, bem como à prevalência de uma cultura jurídica excessivamente formalista junto a seus atores institucionais.
\end{abstract}

Palavras-chave: Juizado Especial Criminal (JECrim), Justiça Criminal, Judicialização de Conflitos, Belo Horizonte

\footnotetext{
* Eduardo Batitucci é doutor em Sociologia pela UFMG e pesquisador do NESP/FJP. Marcus Cruz é doutor em Administração pela UFMG e Pesquisador do NESP/FJP. Andréia Santos é doutora em Sociologia pela UFMG, professora da PUC/MG e pesquisadora do NESP/ FJP. Ludimila Ribeiro é doutora em Sociologia pelo IUPERJ e bolsista de recém-doutor na FGV/RJ. Letícia Godinho é doutoranda em Ciência Política pela UFMG e Pesquisadora do NESP/FJP. <eduardo.batitucci@fjp.mg.gov.br>.
}

\begin{tabular}{|c|c|c|c|c|c|}
\hline Civitas & Porto Alegre & v. 10 & n. 2 & p. 245-269 & maio-ago. 2010 \\
\hline
\end{tabular}




\begin{abstract}
In this article we analyze the innovation provided by the Juizado Especial Criminal (JECrim) within the Criminal Justice System in Brazil, as well as its effective operation - its practices and procedures - and the main characteristics of its discharge proceedings, based on the findings of the research on JECrim of Belo Horizonte/MG. This article consolidates the results of a set of both qualitative and quantitative research on this Judicial Institution, through the analysis of attitudes, values and beliefs of its members, as well as a systematic survey of the judicial flow of cases sentenced. The results point to the questioning of JECrim/ $\mathrm{BH}$ as a relevant instance to resolve conflicts in Belo Horizonte, due to the long average time for the solution procedure of a typical case, given the strong bureaucracy implemented by the court as well as the prevalence of an overly formalistic legal culture along with their institutional actors.
\end{abstract}

Keywords: Small Claim Courts; Criminal Justice; conflicts judicialization; Belo Horizonte

\title{
Introdução
}

De 2004 a 2009, o NESP - Núcleo de Estudos de Segurança Pública - da Fundação João Pinheiro realizou uma série de pesquisas destinadas a compreender o específico funcionamento do Juizado Especial Criminal JECrim de Belo Horizonte. Criado há apenas 15 anos pela Lei 9.9099/1995, ele se constitui uma instância de processamento de crimes considerados pela legislação de "menor potencial ofensivo", e tem sido desde então objeto sistemático de estudo por parte da literatura brasileira. Neste artigo, analisamos a inovação introduzida por essa instância processual no interior do sistema de justiça criminal, seu efetivo funcionamento - suas práticas e procedimentos - e as principais características do seu fluxo processual, a partir dos achados da pesquisas sobre o JECrim do município de Belo Horizonte ${ }^{1}$.

As pesquisas utilizaram métodos qualitativos de observação (pesquisa etnográfica), com o objetivo de apreender atitudes, valores e crenças de seus profissionais. Utilizaram também metodologias quantitativas de processamento dos dados coletados, relativos ao fluxo de processamento das demandas como tempo de processamento e taxa de produtividade do JECrim - e relativos à institucionalização dessa nova arena de resolução de conflitos - tais como características relativas às vítimas, réus e natureza das demandas.

O texto está organizado de maneira a compreender as supostas três mais importantes inovações ocorridas a partir da introdução dos JECrim, a serem esclarecidas abaixo. Essa perspectiva permite, dentre outras coisas, compreender o impacto das motivações contraditórias que estão em sua origem,

1 Obviamente que não se pretende aqui generalizar os dados encontrados para o JECrim de Belo Horizonte para o universo brasileiro; não obstante, eles permitem dialogar com os estudos que buscam uma reflexão acerca do modo de funcionamento do JECrim de maneira geral. 
que vão desde o interesse pragmático de "desafogamento" do Judiciário à experimentação de novas estratégias de solução de conflitos (Chies, 2008: 176).

Em primeiro lugar, a criação dessa nova arena de resolução de conflitos no sistema de justiça brasileiro teve por objetivo se diferenciar das instâncias tradicionais ao introduzir os princípios da oralidade, informalidade, celeridade e economia processual no processamento das demandas. Isso permitiria ao JECrim, em tese, processar com maior rapidez e eficiência econômica as demandas de "menor potencial ofensivo".

Além disso, acreditou-se que o funcionamento do JECrim se aproximaria do sistema norte-americano, apontado como mais democrático (Kant de Lima, 1997), por permitir, com a introdução da transação penal, que os sujeitos do processo pudessem barganhar o seu direito com o sistema judicial.

Por fim, a emergência dos Juizados Especiais Criminais na sociedade brasileira significaria uma alteração profunda na sistemática de aplicação do direito por parte das organizações integrantes do sistema de justiça criminal. Principalmente, porque elas deixariam de se preocupar em realizar uma atividade meramente exegética de subsunção do caso à norma legal, passando a compreender de maneira mais ampla a natureza do conflito levado à esfera institucional, buscando assim uma efetiva solução para o problema. Isso possibilitaria ainda uma diminuição da possibilidade do conflito retornar novamente ao sistema, revestido de um crime ou infração penal mais grave. Ademais, promoveria a incorporação da vítima e do réu como atores relevantes do processo, uma vez que a sistemática do Juizado Especial Criminal passa a ter como um de seus focos a promoção da reconciliação do ofendido com o ofensor. Nesse sentido:

Assiste-se ao surgimento de um novo paradigma, empenhado em responder às debilidades do sistema judiciário e em encontrar novas formas de administrar a justiça, articulado em torno de uma justiça restaurativa... [a qual] propõe um quadro de reflexão sobre os conflitos, os crimes e as respostas aos crimes, mais do que uma teoria ou uma filosofia da justiça (Azevedo, 2005, p. 122).

\section{A busca por maior eficiência processual: a celeridade possível}

Uma das crenças que informa o sistema de justiça tradicional brasileiro postula que, para que o processamento e a punição dos conflitos ocorram de forma ágil e eficiente, sua estrutura deve estar burocratizada, profissionalizada (baseada na racionalidade técnica) e distanciada dos interesses privados, de maneira a se contrapor a um funcionamento seletivo e patrimonialista. Para 
tanto, todas as normas encontram-se previamente estabelecidas, sendo que a discricionariedade dos atores de cada uma das organizações se limita a aplicar determinados procedimentos normatizados. Para Sapori (1995), o domínio do racional legal se vislumbra, no sistema de justiça criminal, nas características de impessoalidade, formalismo, centralização, profissionalização, especialização e documentação. Seriam esses os princípios condutores de uma justiça burocratizada, o que, levado a um extremo, permitiu ao autor a concluir que o processo de produção da justiça criminal brasileira organizar-se-ia segundo uma linha de montagem.

Isso ocorreria, dentre outros motivos, em razão da filiação do sistema de justiça brasileiro à chamada tradição do Civil $L a w^{2}$, que não contempla esferas de discricionariedade para os atores institucionais. Com isso, criou-se uma necessidade exacerbada, por parte dos legisladores, em prever e normatizar todas as ações a serem empreendidas no processamento e julgamento daqueles que suscitaram a quebra da ordem (Kant de Lima, 1997).

Paradoxalmente, a excessiva burocratização e normalização do aparato de justiça brasileiro não impediram a aplicação extremamente seletiva da lei, bem como sua utilização privatista. Pelo contrário, observa-se, mesmo após dois séculos de funcionamento, a aplicação de estigmas legais a determinados comportamentos ou características socioculturais de estratos da sociedade, contaminando o aparato institucional com uma visão ideológica de sua aplicabilidade e, por conseqüência, hierarquizando-o de acordo com as estruturas sociais vigentes, minimizando ou vetorizando sua capacidade de agir como um sistema para a resolução dos conflitos (Paixão, 1982).

Em contraposição, o Juizado Especial Criminal teve como um de seus objetivos se distinguir das instâncias tradicionais introduzindo os princípios da oralidade, informalidade, celeridade e economia processual no processamento das demandas. Ao contrário do modelo tradicional de justiça, a informalização e a oralidade seriam os instrumentos principais que o possibilitariam processar com maior rapidez e eficiência as chamadas demandas de "menor potencial ofensivo".

Conforme destacado por alguns estudos, em virtude do aumento da criminalidade, sobretudo a violenta, o sistema de justiça criminal brasileiro passou a privilegiar o processamento dos casos mais graves; infrações de menor potencial ofensivo eram esquecidas até que o instituto da prescrição ${ }^{3}$ viesse

\footnotetext{
2 Para uma descrição da evolução e característica dos diferentes sistemas de justiça existentes, ver Gilissen (1998).

3 Perda do direito de ação em razão do decurso do prazo.
} 
a operar. Com isso, pode-se observar uma perda de legitimidade do sistema de justiça criminal para o processamento dos conflitos oriundos do cotidiano, principalmente para as camadas menos favorecidas da população, uma vez constatado que as demandas suscitadas por essas não eram devidamente apreciados pela arena institucional encarregada de processá-los.

Por outro lado, o próprio sistema introjetou a crença de que, para pequenos delitos, o processamento longo e completo poderia ser inútil, uma vez que não impedia uma nova ocorrência do evento no futuro, mas, ao contrário, uma grande probabilidade dos envolvidos retornarem ao tribunal protagonizando um conflito mais grave. Diagnosticou-se assim que apenas a atuação pontual e imediata do sistema de justiça criminal, no sentindo de procurar resolver definitivamente o conflito, poderia limitar a possibilidade de seu ressurgimento agravado.

O JECrim se colocou, então, como uma possibilidade de ampliar o acesso à Justiça criminal, alcançando estratos da população limitados não somente pelos altos custos processuais mas também pelo excessivo formalismo que coloniza a linguagem do direito que, reconhecidamente, dificulta a penetração da justiça em muitos setores sociais (Cunha, 2001). Assim, nesta primeira seção, analisamos as características do JECrim de Belo Horizonte relacionadas às hipóteses de maior eficiência no processamento dos casos e de ampliação do acesso à Justiça.

O JECrim foi instalado em Belo Horizonte em 08 de fevereiro de 1996, temporariamente, no subsolo do Fórum da comarca, no centro da cidade. Nesse primeiro momento, a pretensão dessa nova arena judicial era resolver, imediatamente, todas as ocorrências de menor potencial ofensivo verificadas em toda a cidade. Funcionando $24 \mathrm{~h}$ por dia, esperava-se que os cidadãos identificassem prontamente as diferenças existentes entre o procedimento convencional e o sumaríssimo.

Essa experiência durou apenas 20 dias, "quando o Juizado Especial Criminal passou a atender em período integral somente os fatos ocorridos na área interna do perímetro da Avenida do Contorno" (Salgueiro, 2001: 26). Esse momento marca a primeira de várias inversões de foco da instância. Como sua pretensão inicial era aumentar a penetração judicial, principalmente, entre as camadas menos favorecidas, a circunscrição de atuação deveria ser todo o município, e não restringir-se à área central.

Em junho de 1996, paralelamente à redução do horário de atendimento do JECrim ao período de 6 às 24h, houve ainda uma redefinição de sua competência territorial, quando foram excluídas áreas carentes que apresentavam um volume de trabalho para o qual essa instância não estava 
preparada. Assim, mais uma parte do possível público dessa arena foi excluído da solução judicial de seus conflitos.

No princípio do ano de 1999, o Juizado Especial Criminal foi transferido para uma sede própria, na qual poderia aplicar o procedimento de solução de conflitos sem nenhum tipo de estranhamento por parte dos adeptos do simples processamento nem da penalogia tradicional. Localizado em uma região servida por boa rede de transporte público de ônibus e metrô, apesar de fora da área central da cidade, podia ser alcançado de modo relativamente fácil. Assim, a partir da inauguração da nova sede do JECrim, seu atendimento passou a ocorrer da seguinte forma:

- De 6 às $18 \mathrm{~h}$ - todas as ocorrências de apresentação imediata ocorridas dentro da Avenida do Contorno ou na área de funcionamento do JECrim eram encaminhadas a esse;

- De 6 às $18 \mathrm{~h}$ - as ocorrências verificadas fora da área da Avenida do Contorno e do JECrim eram registradas, por meio de Termos Circunstanciados de Ocorrência, nas delegacias de cada área, sendo agendada uma audiência de conciliação para data futura;

- De 18 às $0 \mathrm{~h}$ - todas as ocorrências de apresentação imediata de Belo Horizonte eram encaminhadas para o JECrim.

- De 0 às $6 \mathrm{~h}$ - o JECrim não realizava nenhum atendimento, sendo de responsabilidade das delegacias lavrar o Termo Circunstanciado de Ocorrência e agendar uma data para que as partes comparecessem ao JECrim para a realização da audiência de conciliação.

Interessante notar que a sistemática adotada em termos, principalmente, do horário de funcionamento, mostra o quanto o JECrim de Belo Horizonte estava distante de promover a resolução dos conflitos relativos a uma infração de menor potencial ofensivo. Como a maioria das ocorrências apenas se tornaria objeto de apreciação dos conciliadores muito tempo depois da verificação do fato, é bem provável que as partes já tivessem resolvido o seu conflito na arena privada. Talvez isso ajude a explicar o grande percentual de desistência ${ }^{4}$ verificado nas audiências de conciliação.

Em sua configuração atual ${ }^{5}$, o único Juizado Especial Criminal de Belo Horizonte funciona em uma sede própria, durante o período de 7 às $23 \mathrm{~h}$,

4 A desistência, nesse caso, não precisa ser definitiva, uma vez que a vítima pode "mudar de idéia" até seis meses após a data do fato, prazo em que decai o seu direito de representação. Apesar de não ser muito comum a ocorrência desse tipo de procedimento, é possível que a parte ofendida retorne ao JECrim após a audiência de conciliação, quando ainda não decaiu o seu direito, para exercer a representação em desfavor do ofensor.

5 Importante destacar que desde de setembro de 2001, o JECrim assumiu a competência para processar todas as causas cíveis relativas a acidentes de trânsito cujo valor não ultrapasse o teto 
atendendo as ocorrências de menor potencial ofensivo de toda a comarca. Usualmente, as audiências de conciliação são agendadas pelas delegacias de polícia da cidade, mas o Juizado recebe, apesar de em número muito menor, audiências "imediatas", isto é, aquelas que acabaram de acontecer e nas quais as partes são encaminhadas diretamente ao juizado pela polícia.

No que se refere à arquitetura, o prédio do JECrim é bem moderno, contando com dois andares com as seguintes instalações: no primeiro funcionam a recepção e balcão de informações, a Delegacia de Polícia Civil adida ao Juizado, escritórios para promotores e defensores públicos, uma área com cadeiras para a acomodação do público, sanitários de uso coletivo e o espaço onde se realizam as audiências de conciliação. No segundo, funcionam três salas para a realização das audiências de instrução e julgamento, banheiros privativos para funcionários, escritórios para os juízes e todo o aparato administrativo do Juizado.

O conhecimento de uma infração de menor potencial ofensivo pelo JECrim se inicia com a distribuição do procedimento, momento em que o Termo Circunstanciado de Ocorrência passa a possuir uma feição jurídica. Após esse momento, que consiste apenas na atribuição de um número judicial ao documento policial, verifica-se se a audiência de conciliação já foi agendada e em caso negativo, a data possível de sua ocorrência.

A estruturação do JECrim compreende três tipos de audiências: imediatas, instrução e julgamento, e conciliação. As audiências imediatas são aquelas que ocorrem tão logo o fato é comunicado à autoridade policial. Presentes autor e vítima na delegacia adida do Juizado, esses são imediatamente encaminhados para a conciliação. Esse tipo de procedimento tem ocorrido diariamente entre 7 e $23 \mathrm{~h}$. Com isso, observa-se um primeiro filtro para a solução imediata dos conflitos: apenas os Termos Circunstanciados de Ocorrências lavrados nessa delegacia são encaminhados para audiência imediata, significando que provavelmente apenas os pequenos delitos ocorridos na vizinhança ou na circunscrição da delegacia adida são objetos de conciliação logo após a sua ocorrência.

As audiências de instrução e julgamento são aquelas que ocorrem quando a audiência de conciliação não foi capaz de pôr termo ao conflito por meio

de quarenta salários mínimos. Essa transferência teve como justificativa o fato de esse Juizado possuir um pequeno número de processos criminais (quando comparado com a demanda do Juizado Especial Cível - JECÍVEL) e, por isso, poderia conciliar a função tanto de resolver os pequenos conflitos da seara criminal como os provenientes dos acidentes de trânsito ocorridos na capital cujo valor da causa não fosse superior a 40 salários mínimos. Com isso, cria-se uma duplicidade de competências que acaba por comprometer a realização de audiências criminais imediatas, posto que o tempo "livre" passou a ser ocupado com causas da seara "cível". 
da realização de um acordo de composição de danos civis entre as partes, da transação penal, da suspensão condicional do processo ou do arquivamento do caso. Com isso, o processo é inaugurado por meio do andamento da denúncia ou queixa segundo o rito sumaríssimo ${ }^{6}$, e as audiências ocorrem nos dias úteis entre $7 \mathrm{~h} 30$ e $17 \mathrm{~h} 30$.

No que se refere às audiências de conciliação agendadas previamente pela autoridade policial civil, essas ocorrem durante os dias úteis, em três turnos, nos horários de 9h-11h30, 15h-17h30 e 18h-20h30. Cada um desses turnos suporta até 60 audiências de conciliação, segundo determinações do juiz, promotor e defensor público. Para a realização de todos os tipos de audiências, de conciliação e de instrução e julgamento, essa instância do Poder Judiciário conta hoje com 6 Juízes, 6 Promotores Públicos e 8 Defensores Públicos.

Para auxiliar as primeiras análises, realizou-se em 2004 um levantamento dos dados sistematizados pelo próprio JECrim de Belo Horizonte. No entanto, observou-se que o Juizado apenas possuía indicadores quantitativos relativos à movimentação processual: número de processos distribuídos (iniciados), baixados (solucionados em definitivo, indo para o arquivo) e julgados (AIJ); e número de audiências realizadas. Não havia informações sistematizadas relativas a autores e vítimas, e não foram disponibilizadas as relativas ao número de processos por natureza da infração, o que impediu, em um primeiro momento, a realização de comparações com pesquisas já existentes à época (por exemplo, Azevedo, 2004, para o caso do JECrim de Porto Alegre; Cunha, 2001 e Kant de Lima, Amorim e Burgos, 2004, para o Rio de Janeiro).

A natureza das informações sistematizadas no banco de dados do JECrim de Belo Horizonte privilegiava, pois, aspectos de natureza administrativa (como a produtividade dos juízes) e de acompanhamento processual, denunciando uma ausência simbólica de atribuição de importância aos aspectos sociais envolvidos nos conflitos administrados por essa instituição.

É importante destacar, no que se refere aos casos remetidos aos Juizados Especiais Criminais, que os envolvidos devem, necessariamente, submeter-se à autoridade policial civil antes de serem levados à presença de um auxiliar da justiça. Com isso, conforme destaca Salgueiro (2001), muitos casos têm seu desfecho na própria instância policial, indicando que a vasta maioria das demandas é de fato mediada pelas polícias, não percorrendo o caminho de sua judicialização através do atendimento pelo judiciário.

6 Procedimento sumaríssimo é aquele no qual todos os atos processuais estão concentrados em uma única audiência na qual é realizada a apresentação de provas, a oitiva das testemunhas de acusação e defesa, o interrogatório do réu, o depoimento da vítima e, ao final, após a manifestação do Ministério Público e Defensoria (pública ou privada), é proferida a sentença. 
Figura 1: Produtividade dos Juizados Especiais Criminais (processos distribuídos - processos julgados)

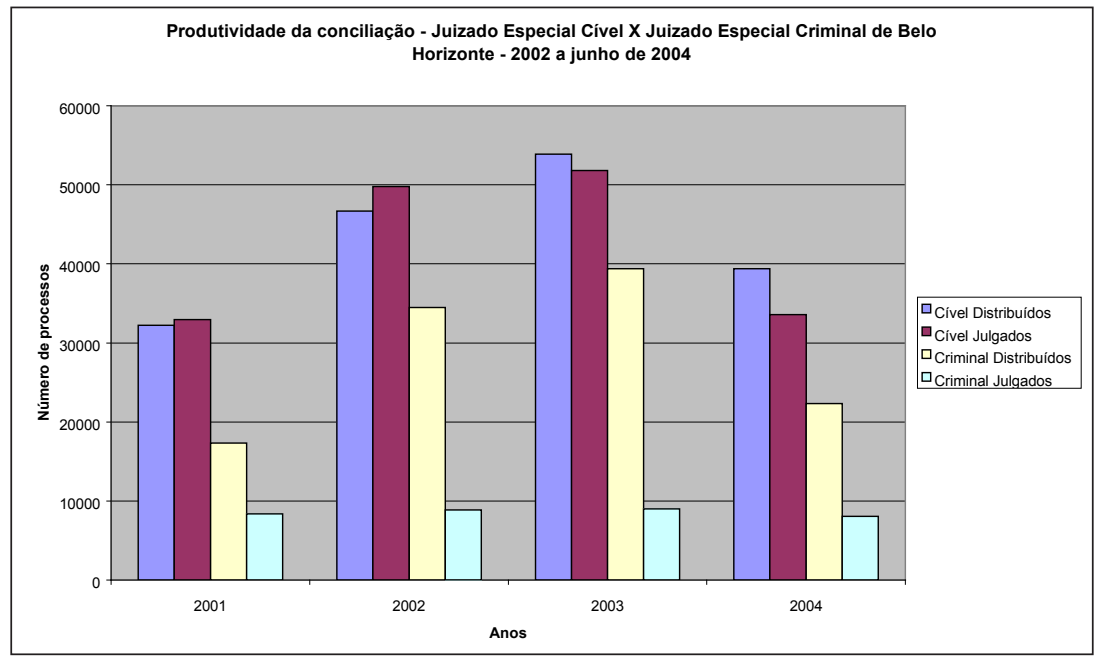

Fonte: Tribunal de Justiça do Estado de Minas Gerais.

Essa crença se coaduna com a pesquisa feita com os dados dos processos baixados no ano de $2006^{7}$. Observou-se, em primeiro lugar, que um alto número de processos $(72,2 \%$ do total da amostra) foi arquivado sem ter ocorrido qualquer audiência.

Ainda, do total de processos onde houve pelo menos uma primeira audiência (27,8\%), ou seja, onde as partes foram ouvidas por conciliadores, $40 \%$ desistiu de representar contra o réu na justiça e dar seguimento ao processo, cabendo ao JECrim apenas carimbar os autos e aguardar o prazo decadencial legal de 6 meses. Assim, do total de processos pesquisados, em apenas $16,5 \%$ dos casos houve prosseguimento normal do processo, com audiências de conciliação, oferecimento de transação penal e outros.

Quando analisamos os passos que vítimas e réus cumprem no decorrer do processo, três momentos merecem especial atenção (Tabela 1). Primeiro, interessa observar se réus e vítimas se comprometem a comparecer ao judiciário para a audiência de conciliação, ritual que faz parte da lavratura do TCO nas delegacias de Polícia Civil em Belo Horizonte. Em segundo lugar,

7 Do universo de 17.000 processos tramitados no JECrim, baixados no ano de 2006, selecionouse uma amostra aleatória estatisticamente significativa de 603 processos. 
parece importante entender o binômio representação-desinteresse em virtude do fato de que a representação por parte da vítima e a eventual manifestação dela de desinteresse em seguir com o processo são momentos fundamentais para o seguimento do fluxo do processo no JECrim. No primeiro caso, se não houver representação imediata no caso dos crimes de ação penal pública condicionada, a probabilidade é que o processo seja encerrado por decurso do prazo decadencial de 6 meses, como acontecerá no segundo caso.

Em ambos os casos, a desistência por parte da vítima do direto de processar o réu é indicativa, em certa medida, tanto do papel da polícia como instância mediadora quanto das fragilidades institucionais do JECrim como instância processual e de resolução de conflitos, especialmente em virtude do demorado prazo necessário para o término do processo (como veremos adiante).

De fato, menos de $37 \%$ de réus e vítimas, em todas as ocorrências, assina compromisso de comparecer ao judiciário, o que indica a baixa institucionalização sistêmica do JECrim como instância de resolução de conflitos.

Tabela 1: Natureza do fato registrado no Termo Circunstanciado de Ocorrência (TCO) dos processos baixados no JECrim-BH em 2006 segundo posicionamento de réu e vítima em momentos do processo

\begin{tabular}{lcccc}
\hline \multirow{2}{*}{$\begin{array}{c}\text { Natureza do } \\
\text { Fato no TCO }\end{array}$} & $\begin{array}{c}\text { Lavrou termo de } \\
\text { Comparecimento } \\
\text { em Audiência (\%) }\end{array}$ & $\begin{array}{c}\text { Lavrou termo de } \\
\text { Comparecimento } \\
\text { em Audiência (\%) }\end{array}$ & $\begin{array}{c}\text { Lavrou termo de } \\
\text { Representação } \\
\text { contra o Réu (\%) }\end{array}$ & $\begin{array}{c}\text { Manifestou } \\
\text { Desinteresse em } \\
\text { seguir com o } \\
\text { Processo (\%) }\end{array}$ \\
\hline Abalroamento & 0,0 & 0,0 & 0,0 & 90,9 \\
\hline Ameaça & 26,9 & 35,7 & 29,3 & 87,3 \\
\hline $\begin{array}{l}\text { Lesão Corporal } \\
\text { (exclui Trânsito) }\end{array}$ & 31,7 & 36,4 & 28,0 & 87,3 \\
\hline Vias de Fato & 35,6 & 34,7 & 34,7 & 90,3 \\
\hline
\end{tabular}

Fonte: Processos arquivados no Tribunal de Justiça de Minas Gerais

Igualmente é bastante baixo o número de vítimas que representa contra o autor, não atingindo $35 \%$ no patamar mais alto. Isso pode se dever às próprias circunstâncias da ocorrência e da relação entre vítima e réu, mas também pode estar vinculado ao trabalho da polícia como instância mediadora e às dificuldades institucionais do JECrim no cumprimento deste papel. Sustentando ainda as inferências feitas, constatou-se ser muito alto o nível de desinteresse manifestado pela vítima em dar prosseguimento ao processo, sempre acima de $87 \%$. 
Estas constatações adquirem um tom mais sistêmico quando observamos o fluxo destas demandas dentro do JECrim (Tabela 2). Neste caso, das quatro naturezas consideradas (excluiu-se as Lesões Corporais no Trânsito), que correspondem a $53,8 \%$ do total de processos da amostra, em apenas 30\% deles haverá alguma audiência de conciliação. Em metade dos processos que chegar a essa etapa, a vítima afirmará o seu desinteresse em prosseguir com a ação. Finalmente, em apenas 3,1\% do total dos processos destas quatro naturezas será oferecida transação penal. Estas estatísticas demonstram o enorme desafio institucional colocado ao Juizado Especial Criminal de Belo Horizonte, especialmente em virtude da morosidade associados a esses momentos processuais, como veremos a seguir.

Tabela 2: Natureza do fato registrado no Termo Circunstanciado de Ocorrência (TCO) dos processos baixados no JECrim-BH em 2006 segundo momentos do fluxo processual

\begin{tabular}{|c|c|c|c|c|}
\hline \multirow[b]{2}{*}{$\begin{array}{c}\text { Natureza do Fato } \\
\text { no TCO }\end{array}$} & \multirow[b]{2}{*}{$\begin{array}{l}\% \text { do total de } \\
\text { processos da } \\
\text { Amostra }\end{array}$} & \multirow[b]{2}{*}{$\begin{array}{l}\text { \% do total de } \\
\text { processos desta } \\
\text { natureza que } \\
\text { atingiu a } 1^{\mathrm{a}} \\
\text { Audiência de } \\
\text { Conciliação }\end{array}$} & \multicolumn{2}{|c|}{ Na 1 ${ }^{a}$ Audiência de Conciliação } \\
\hline & & & $\begin{array}{c}\text { \% do total de } \\
\text { processos desta } \\
\text { natureza onde a } \\
\text { vítima manifestou } \\
\text { desinteresse }\end{array}$ & $\begin{array}{c}\text { \% do total de } \\
\text { processos desta } \\
\text { natureza onde } \\
\text { houve transação } \\
\text { penal }\end{array}$ \\
\hline Abalroamento & 2,2 & 7,7 & 7,7 & 0,0 \\
\hline Ameaça & 24,7 & 30,1 & 16,4 & 3,4 \\
\hline $\begin{array}{l}\text { Lesão Corporal } \\
\text { (exclui Trânsito) }\end{array}$ & 16,1 & 30,5 & 14,7 & 3,2 \\
\hline Vias de Fato & 10,8 & 34,4 & 17,2 & 3,1 \\
\hline $\begin{array}{l}\text { \% sobre Total dos } \\
\text { Processos destas } \\
\text { naturezas }\end{array}$ & 100 & 30,2 & 15,7 & 3,1 \\
\hline $\begin{array}{l}\% \text { sobre o Total dos } \\
\text { Processos da Amostra }\end{array}$ & 53,8 & 16,2 & 8,5 & 1,7 \\
\hline
\end{tabular}

Fonte: Processos arquivados no Tribunal de Justiça de Minas Gerais

As limitações até aqui anunciadas se tornam mais evidentes quando levamos em consideração os tempos do fluxo dos processos no JECrim de Belo Horizonte (Tabela 3).

Uma primeira limitação acerca da estruturação dessa nova modalidade de processamento reside no tempo necessário à Polícia Civil para confeccionar o Termo Circunstanciado de Ocorrência, prazo estimado em 46 dias. De fato, em apenas $15,2 \%$ dos casos o TCO foi registrado no mesmo dia; em apenas $7,4 \%$ dos casos, na mesma semana. Por outro lado, em 32,6\% dos casos o TCO só foi produzido após 30 dias do fato. Este longo prazo aponta para duas possibilidades: a primeira, de que a polícia procura mediar o conflito, evitando 
o seu registro formal (Paixão, 1982; Kant de Lima, 1997; Batitucci, 2006); a segunda, de que a Polícia Civil de Minas Gerais não possuía condições institucionais para atender este tipo de demanda em Belo Horizonte, retardando o seguimento do processo.

TABELA 3: Tempos do fluxo dos processos baixados no JECrim-BH em 2006

\begin{tabular}{|c|c|c|c|c|}
\hline $\begin{array}{l}\text { Tempo decorrido entre } \\
\text { (em dias) }\end{array}$ & $\begin{array}{l}\text { A Data do Fato e } \\
\text { a Comunicação } \\
\text { na Delegacia }\end{array}$ & $\begin{array}{c}\text { A Data do Fato e } \\
\text { o Registro do } \\
\text { TCO }\end{array}$ & $\begin{array}{l}\text { A Data do Fato e } \\
\text { o } 1^{\circ} \text { Carimbo da } \\
\text { Fase Judicial }\end{array}$ & $\begin{array}{c}\text { A Data do Fato e } \\
\text { o Último } \\
\text { Carimbo da } \\
\text { Fase Judicial }\end{array}$ \\
\hline Mínimo & 0 & 0 & 0 & 0 \\
\hline Máximo & 373 & 709 & 720 & 754 \\
\hline Média & 1,9 & 48,02 & 62,12 & 172,31 \\
\hline $\begin{array}{l}\% \text { sobre o Total dos } \\
\text { Processos da Amostra } \\
\text { onde esta Fase aconteceu } \\
\text { em até } 30 \text { dias }\end{array}$ & 63 & 46,7 & 34,6 & 2,7 \\
\hline $\begin{array}{l}\text { Tempo Médio Decorrido } \\
\text { em cada Fase (dias) }\end{array}$ & 2 & 46 & 16 & 110 \\
\hline
\end{tabular}

Fonte: Processos arquivados no Tribunal de Justiça de Minas Gerais.

Outro grande problema é evidenciado no tempo perdido entre a burocracia da Polícia Civil e a do Judiciário. Observou-se o prazo médio de 16 dias entre a finalização do TCO pela Polícia e a recepção do mesmo pelo Judiciário. Na verdade, apenas 5,7\% dos processos foram recebidos no mesmo dia e $25,4 \%$ em até 5 dias. Por outro lado, em $14 \%$ dos casos o prazo foi maior do que 25 dias.

Mas o maior dos problemas constatados se relaciona ao tempo gasto para a conclusão do procedimento propriamente judicial. $\mathrm{O}$ tempo médio observado foi de 110 dias, ou três meses e meio, obviamente muito alto para um procedimento que pretende valorizar a oralidade, informalidade e economia processual. A análise evidenciou que, dos 591 processos pesquisados, em apenas 16 casos ou 3,5\% da amostra válida, o processo demorou menos que 30 dias. A Figura 2 apresenta o histograma da distribuição dos processos nesta variável, evidenciando que um número significativo dos processos demorou entre 170 e 220 dias para ser finalizado ${ }^{8}$.

8 Foram retirados deste cálculo os casos em que houve prescrição do crime e onde se aguardou o cumprimento de prazo decadencial. Assim sendo, o cálculo foi realizado dentre 80 processos. 
Figura 2: Histograma dos processos baixados no JECrim-BH em 2006 segundo tempo decorrido entre a data do fato e a conclusão do processo*

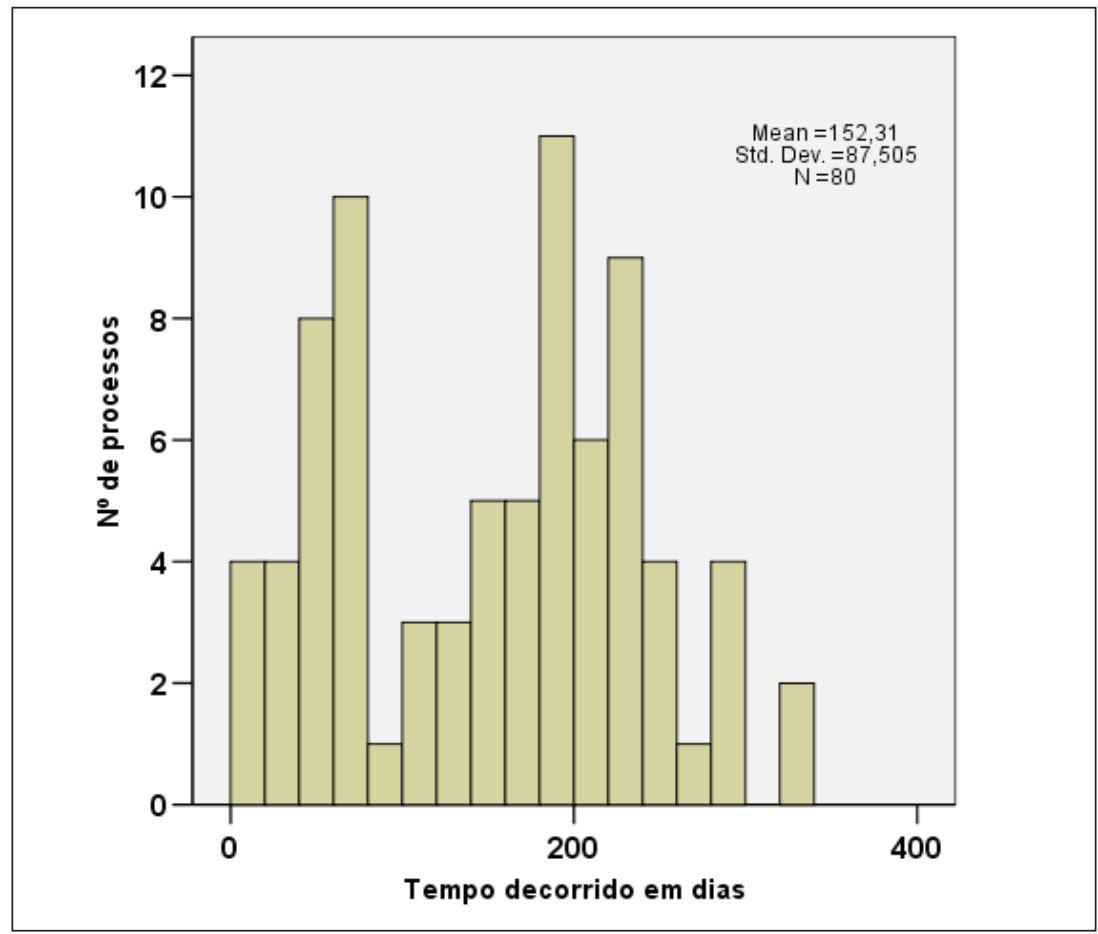

Fonte: Processos arquivados no Tribunal de Justiça de Minas Gerais.

* Alguns processos foram excluídos em virtude de alta distorção na distribuição da amostra.

Levando-se em consideração o tempo gasto apenas nos trabalhos do judiciário, observamos que 17,6\% dos processos levaram até 30 dias para serem concluídos, enquanto que $45 \%$ dos processos levaram entre 90 e 210 dias.

Um elemento fundamental que determina a duração dos processos são as realizações das audiências, sejam as de conciliação, sejam as de outros tipos. Em virtude de limitações institucionais do JECrim-BH (como espaço físico disponível, número de conciliadores disponíveis diante da demanda, horário limitado de funcionamento, etc.) e em virtude das dificuldades inerentes aos procedimentos de citação de réu e vítima, a diferença de tempo entre a marcação e a realização das audiências toma um tempo precioso desses procedimentos, como podemos observar na Tabela 4 . 
Tabela 4: Tempos do fluxo dos processos baixados no JECrim-BH em 2006

\begin{tabular}{|c|c|c|c|}
\hline $\begin{array}{l}\text { Tempo decorrido entre } \\
\text { (em dias) }\end{array}$ & $\begin{array}{l}\text { A Data do Fato e a } \\
\text { Marcação da } \\
1^{\text {a Audiência }}\end{array}$ & $\begin{array}{l}\text { A Data do Fato e } \\
\text { a Realização da } \\
1^{\mathrm{a}} \text { Audiência }\end{array}$ & $\begin{array}{c}\text { A Data do Fato e } \\
\text { a } 1^{\circ} \text { Pena }\end{array}$ \\
\hline Mínimo & 0 & 0 & 0 \\
\hline Máximo & 273 & 336 & 333 \\
\hline Média & 30,8 & 69,01 & 75,92 \\
\hline $\begin{array}{l}\% \text { sobre o Total dos } \\
\text { Processos da Amostra onde } \\
\text { esta Fase aconteceu em até } \\
30 \text { dias }\end{array}$ & 15,3 & 13,5 & 1,3 \\
\hline $\begin{array}{l}\text { Tempo Médio Decorrido em } \\
\text { cada Fase (dias) }\end{array}$ & 30 & 38 & 7 \\
\hline
\end{tabular}

Fonte: Processos arquivados no Tribunal de Justiça de Minas Gerais.

A despeito da primeira audiência de conciliação poder ser agendada junto ao procedimento do TCO efetivado pela Polícia Civil (46\% das audiências foram marcadas no dia do fato), sua realização só acontecerá, em média, 38 dias depois da data marcada, sendo que em apenas $2,6 \%$ dos processos a audiência de conciliação aconteceu no mesmo dia do fato.

Por outro lado, não obstante o curto prazo observado entre a realização da audiência e a conclusão dos processos (7 dias), o prazo médio total de 176 dias decorridos entre a data do fato e o último carimbo do judiciário se mostra extremamente longo.

Tabela 5: Tempos do fluxo dos processos baixados no JECrim-BH em 2006

\begin{tabular}{|c|c|c|c|}
\hline $\begin{array}{l}\text { Tempo decorrido entre } \\
\text { (em dias) }\end{array}$ & $\begin{array}{c}\text { Fase Policial - } \\
\text { Boletim de } \\
\text { Ocorrência e TCO }\end{array}$ & $\begin{array}{l}\text { Fase Judicial - } \\
\text { Audiências }\end{array}$ & $\begin{array}{c}\text { Tempo Total Médio } \\
\text { de Duração do Processo } \\
\text { (em dias) }\end{array}$ \\
\hline $\begin{array}{l}\text { Tempo Médio Decorrido em } \\
\text { cada Fase (dias) }\end{array}$ & 48 & 110 & 176 \\
\hline $\begin{array}{l}\% \text { sobre o Total dos } \\
\text { Processos da Amostra onde } \\
\text { esta Fase aconteceu em até } \\
30 \text { dias }\end{array}$ & 46,7 & 2,7 & 2,7 \\
\hline
\end{tabular}

Fonte: Processos arquivados no Tribunal de Justiça de Minas Gerais. 
As conclusões que podemos extrair dos tempos e características levantadas apontam para o sério questionamento do JECrim-BH como uma instância célere de resolução de conflitos. Apesar da literatura recomendar que esse tipo de análise de tempo do fluxo processual seja feita para cada tipo de crime individualmente (porque implicariam padrões diferenciados de processamento), o cálculo do tempo de processamento dos crimes em geral pelo JECrim foi realizado com vistas a saber se essa instituição cumpre com os pressupostos da celeridade e economia processual ${ }^{9}$.

O tempo necessário ao JECrim para processamento de seus casos em geral (110 dias) não é muito inferior ao tempo prescrito do CPP (Código de Processo Penal) para o processamento de crimes comuns pela instância tradicional (129 dias para réu preso e 179 dias para réu solto) ${ }^{10}$. Portanto, os tempos observados no fluxo dos processos no Juizado ajudam a evidenciar que o JECrim-BH apresenta importantes limitações institucionais para o exercício tempestivo das atividades a que se propõe, dentro dos ideais originais previstos na Lei dos Juizados Especiais.

Além das razões associadas à prevalência das polícias como atores fundamentais para a mediação de conflitos em Belo Horizonte, é muito provável que estas limitações se devam ao modelo de burocratização implementada pelo JECrim, bem como à prevalência de uma cultura jurídica excessivamente formalista, com a qual o JECrim-BH ainda não se mostrou capaz de romper. Isso se mostrará evidente nas seções a seguir, estando ainda associado ao fato de que uma excessiva preocupação com a eficiência processual acabou por privilegiar uma produção em série de audiências, em detrimento de uma perspectiva mais substantiva no tratamento do conflito.

\section{As audiências de conciliação: entre a restauração e o formalismo}

Uma das causas apontadas pela literatura para explicar a pouca eficácia das instâncias tradicionais de justiça do sistema brasileiro é o fato de estarem

\footnotetext{
9 Assim, importava indagar, por exemplo, se o tempo despendido por essa instância judicial é, em geral, menor que o tempo necessário para justiça tradicional fazê-lo. Contudo, essa pergunta não pode ser tão facilmente respondida, à medida em que a grande maioria das análises empíricas existentes no Brasil sobre tempo de processamento refere-se a crimes de homicídio (Ribeiro et al. 2009; Batitucci et al., 2006; Vargas et al., 2005; Pinheiro et al, 1999). Apenas a título de exemplo, em Minas Gerais, o tempo médio de processamento do crime de homicídio pelas varas criminais é de 1580 dias, 5 vezes o prescrito pelo Código de Processo Penal (Ribeiro et al., 2009).

${ }_{10}$ A comparação com outros Juizados Especiais não é possível, pois não há dados sobre o tempo de processamento do JECrim em outras localidades.
} 
dirigidas para o mero processamento e punição dos conflitos (Kant de Lima, 1997). Essa lógica primordialmente retributiva seria confrontada pela emergência dos Juizados Especiais Criminais, que instituiriam um modelo alternativo de resolução de conflitos.

O objetivo de uma estratégia restaurativa ${ }^{11}$ no âmbito da justiça criminal teria por fim diminuir ou eliminar, em última instância, o sentido retributivo (vingativo) e expiatório da penalogia tradicional. (Braithwaite, 2006). A própria nomenclatura restaurativa estaria incompleta, no sentido de que essas propostas teriam como foco não apenas um retorno ao estado de coisas anterior à ocorrência do fato (muitas vezes impossível) como também a recriação do sucedido, a partir de sua discussão entre o ofensor e o ofendido, lançando um novo olhar com relação ao mesmo.

O conceito de justiça restaurativa recobre uma grande possibilidade de programas. A mediação dos conflitos, uma das possibilidades contidas nas estratégias de justiça restaurativa, introduziria a possibilidade de atuar impedindo uma estigmatização dos envolvidos, principalmente o réu; favoreceria o diálogo entre o ofensor e o ofendido; e acenaria para possíveis resultados não punitivos e recriadores, quando possível (Von Hirsch et al., 2003; Chies, 2008).

Nas modalidades de justiça restaurativa, as vítimas teriam uma maior oportunidade de expressar suas histórias e serem ouvidas. Coloca-se a possibilidade de seu empoderadamento a partir do confronto com o ofensor e da participação em uma tomada de decisão acerca da penalidade apropriada. Os ofensores, por outro lado, são chamados a assumir a responsabilidade por seu comportamento.

Ao se colocar como objetivo dar conta do complexo conjunto de determinantes do conflito e recolocar as partes em papel protagonístico na dinâmica de sua solução, essas estratégias de justiça se distanciariam da parcialidade e seletividade características das instâncias tradicionais de processamento judicial. Essas, ao transformar os conflitos sociais em contendas jurídicas, retirá-los-ia das partes, fragmentando-os e reconfigurando-os de acordo com sua lógica de funcionamento - no caso brasileiro, uma lógica extremamente privatista e formalista.

\footnotetext{
${ }^{11}$ É importante notar que a Lei 9099/1995 fala de conciliação e transação penal, mas não de mediação. A esse respeito, diferenciam-se os procedimentos de conciliação e mediação, no sentido de que a primeira tende a ignorar o conflito, enquanto que a segunda busca restaurá-lo e recriá-lo. Não obstante, pelo menos na literatura brasileira que se ocupa do JECrim, fala-se de maneira incontestada acerca de uma arena de mediação $e$ de justiça restaurativa (ou, pelo menos, que se propõe a tanto) e por isso é importante que esse aspecto seja analisado a partir dessas duas perspectivas.
} 
Assim, a emergência dos Juizados Especiais Criminais na sociedade brasileira supostamente implicaria uma alteração profunda na sistemática de aplicação da lei por parte das organizações integrantes do sistema de justiça criminal. Para confirmar essa hipótese, realizamos pesquisa etnográfica das chamadas Audiências de Conciliação do JECrim-BH, buscando verificar em que medida elas cumprem com os ideais de justiça restaurativa; se o tipo de mediação ou conciliação que oportunizam são capazes de responder efetivamente aos conflitos que se colocam.

Em princípio, observou-se que, das audiências acompanhadas, a maioria das demandas apresentadas teve seu desfecho na própria Audiência de Conciliação. No entanto, quais os termos da mediação ou da conciliação operada?

Ao contrário do que ocorre nas Audiências de Instrução e Julgamento, nas quais os atores são especialmente constituídos pelo Estado, as atividades relativas à conciliação são realizadas por conciliadores voluntários, em regra, estudantes do curso de graduação de direito. Esses operadores, denominados pela Lei 9.099/95 de auxiliares da justiça, devem estar cursando no mínimo o $3^{\circ}$ período e devem se submeter a um curso de capacitação de 20 horas/aula.

Contudo, conforme constatado a partir das observações e entrevistas realizadas no JECrim, foi possível verificar que muitos conciliadores iniciam sua atividade antes mesmo da realização do curso. Isso parece ocorrer, principalmente, porque um estudante rapidamente abandona as funções de auxiliar da justiça por outro estágio. Um dos maiores problemas da conciliação é, exatamente, a alta rotatividade dos conciliadores: entre os anos de 1999 e 2004 passaram cerca de 350 conciliadores por aquela seção. Em parte, isso se deve ao fato de não haver critérios claramente definidos para a seleção dos mesmos.

Durante o período de funcionamento, seguranças contratados de empresa privada circulam no corredor para criar uma sensação de ostensividade. Ressalva-se que essa é uma instância do Estado e, por isso, faria jus ao policiamento ostensivo estatal. Contudo, ao contrário do que ocorre no Fórum da Capital, foram contratados seguranças particulares como mecanismo para assegurar a garantia da ordem entre os integrantes de uma parcela da sociedade que é vista como distinta da restante.

Até o ano de 2002, os conciliadores e demais operadores da justiça eram obrigados a trajar uma beca preta como forma de demonstrar às partes, simbolicamente, que estavam diante do inexorável Poder Judiciário. Com o passar do tempo, essas estratégias de ostentação da diferença existente entre os atores do conflito e os atores do sistema de justiça foram sendo relaxadas. 
Mas mesmo após o banimento das becas, os conciliadores distinguemse nitidamente dos litigantes, em termos de postura e vestimenta. Uma vez que as partes foram acomodadas na sala de conciliação, o auxiliar da justiça realiza uma breve leitura do procedimento para os litigantes, explicando as atribuições do JECrim. Em seguida, pede para que cada um dos envolvidos descreva, sumariamente, a querela. Um dos grandes problemas verificados na esmagadora maioria das audiências foi a linguagem utilizada pelos conciliadores, carregada de termos técnicos, não sendo compatível com o entendimento comum das pessoas leigas.

Isso ocorre porque, em geral, estudantes de direito, em sua maioria com bom nível socioeconômico, identificam-se apenas superficialmente com a avassaladora maioria dos conflitos que lhe são apresentados, característicos de realidades sociais bastante distintas das suas. Muito jovens e com pouco treinamento para lidar com situações críticas, o uso simbólico da autoridade do Estado da qual estão investidos se traduz por meio do recurso à construção da distância cognitiva entre eles e os querelantes, hierarquizando a relação de conciliação.

Figura 3: Layout das salas de conciliação

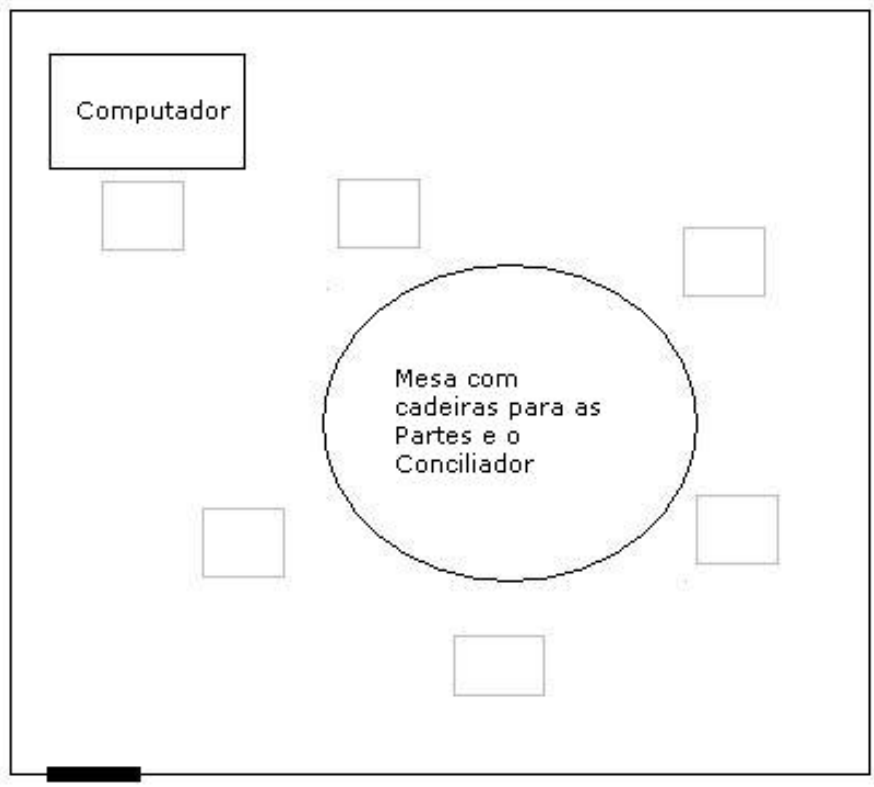

Fonte: Ribeiro, Cruz e Batitucci, 2004. 
Ademais, os conciliadores são claramente pressionados a realizar um grande número de audiências por turno e de forma breve. Na dinâmica de processamento do JECrim, o ritmo da conciliação e da mediação é ditado pela escala e há uma pressão inexorável sobre os coordenadores, que delineia um sistema em que o acordo é extraído sem o menor entendimento do que seria a Justiça e qual deveria ser o real papel de um provável mediador/restaurador de conflitos.

Portanto, muito mais do que a preocupação em solucionar pequenos delitos, o foco do JECrim de Belo Horizonte consiste em processar e punir, com absoluta eficiência, as perturbações à ordem que chegam ao seu conhecimento. Não há preocupação com o destino das partes, sendo algo que escapa à sua competência.

Essa preocupação exacerbada do JECrim-BH com a eficiência possibilita, de fato, a realização de audiências de conciliação rápidas e eficazes; a grande maioria dessas consegue levar o procedimento a um desfecho que, em geral, se consolida na transação penal. Contudo, se por um lado, o não tratamento de cada caso como se fosse único possibilita a realização de um número maior de transações penais e, por conseguinte, uma maior produtividade, por outro, esse fenômeno demonstra uma inversão de prioridades dessa instância do Poder Judiciário.

\section{As audiências de instrução e a conclusão do processo: a justiça informal em linha de montagem}

Os Juizados Especiais Criminais integrariam, a princípio, uma lógica de informalização entendida não como renúncia do Estado ao controle de condutas e alargamento das margens da tolerância, mas como a procura de alternativas de controle mais eficazes e menos onerosas. Segundo Kant de Lima, Amorim e Burgos (2004) isso se atesta, principalmente, a partir da possibilidade do acusado de determinado crime poder transacionar sua pena com o sistema de justiça criminal.

Apontou-se no início deste trabalho que o sistema de justiça brasileiro, devido principalmente a sua vinculação história com o sistema da Civil Law, estaria organizado segundo uma lógica extremamente formalista, que não contempla esferas de discricionariedade para os atores institucionais ou espaços para a negociação entre eles. Em um cenário como esse, não há espaço para a barganha entre os envolvidos em um determinado conflito e os atores do sistema de justiça, uma vez que não se pretende a produção de uma verdade, mas a descoberta dessa, pelo juiz, a partir dos fatos trazidos pelas partes ao processo. 
Pode-se dizer assim que, no Brasil, a justiça criminal pode ser entendida como o lugar primordial da codificação, uma vez que todo o aparato institucional é movimentado segundo normas formais criadas a partir da orientação dogmática jurídica vigente. Essa conjunção de atividades de exegese da lei que conformam o sistema de justiça dificilmente alcançarão a solução dos conflitos, mas apenas o seu conhecimento pela arena institucional e, por conseguinte, o atribuição de uma pena padrão para aquele provocou uma perturbação na ordem (Kant de Lima, 2000).

A transação penal, figura jurídica inserida pelos art. 75 e 76 da Lei 9.099/1995 ${ }^{12}$, tem sido apontada como a maior inovação apresentada pelos Juizados Especiais Criminais. A transação penal institui a possibilidade da promotoria barganhar a pena com o acusado, pressionando-o a aceitar uma sanção imediata em detrimento de esperar por uma ao final do processo penal - que seria extremamente dispendioso para o judiciário e para as partes (Kant de Lima, 1997).

Essa inovação aproximaria o modelo instituído no JECrim com a sistemática do due process of law norteamericano, a partir da materialização do procedimento negociado, contraposto ao formalmente hierarquizado do procedimento convencional brasileiro. Para Kant de Lima (1997), a prevalência do sistema de barganha no aparato institucional norteamericano decorre de sua ênfase no controle e resolução de conflitos. Com isso, a verdade do caso, nesse sistema, não é colocada a priori pelos envolvidos por meio das provas trazidas ao tribunal, mas negociada sistematicamente entre os atores e vítimas do delito e o aparato institucional encarregado de sua solução.

Como explicitado anteriormente, no momento em que chegam ao JECrim, os envolvidos são encaminhados a uma audiência preliminar, conduzida por um conciliador. Essa audiência deve ser encaminhada segundo os princípios da oralidade, informalidade e economia processual. Uma vez finalizada a parte de reconstituição dos fatos pelos envolvidos, os operadores da justiça esclarecem às partes sobre a possibilidade de conciliação entre elas pela via da composição dos danos que, se aceita, implica na renúncia do direito de representação ou queixa (Art. 74 da Lei 9.099/1995). Contudo, esse acordo nem sempre é viável, já que certos direitos não admitem a possibilidade de negociação. Assim, caso a composição de danos não seja plausível, o

${ }^{12} \mathrm{O}$ art. 98, I, da Constituição Federal possibilitou a inserção desse instituto penal no direito brasileiro. Parte da literatura jurídica vê fundamentando esse empreendimento uma racionalidade neoliberal, à medida em que o consequente esvaziamento das prisões atenderia a uma lógica seletiva, segundo a qual que essa modalidade de despenalização privilegiaria os chamados consumidores ativos em detrimento dos consumidores falhos (aos quais corresponderia, em contrapartida, a penalogia tradicional e neutralizadora da privação da liberdade) (Azevedo et al., 2008, p. 55). 
conciliador alertará aos envolvidos sobre a possibilidade do ofendido exercer o seu direito de queixa nesse momento ou no máximo até seis meses após a data do fato ${ }^{13}$. Caso a vítima indique o seu desejo em processar o autor do fato ou no caso de se tratar de delitos de ação penal pública incondicionada, o promotor de justiça pode propor a realização da transação penal, a suspensão condicional do processo ou requerer o arquivamento do caso.

Pode-se dizer que a transação penal dá ao autor do fato uma possibilidade de escolha, ou seja, aceitar a aplicação imediata de uma pena não privativa de liberdade ou prosseguir com o processo até uma condenação final (Kant de Lima, Amorim e Burgos, 2004). Caso recuse a proposta ou não preencha os requisitos indispensáveis a sua concessão, o procedimento atinge a sua segunda fase: a instrução e julgamento.

Diferentes das salas de conciliação, as reservadas para as audiências de instrução possuem o layout tradicional das salas do Poder Judiciário, separando-se a sociedade do Estado; Promotores e Defensores se posicionam, fisicamente, em lados opostos às partes, conforme pode ser visto na figura abaixo:

Figura 4: Layout das salas onde ocorrem as audiências de instrução e julgamento

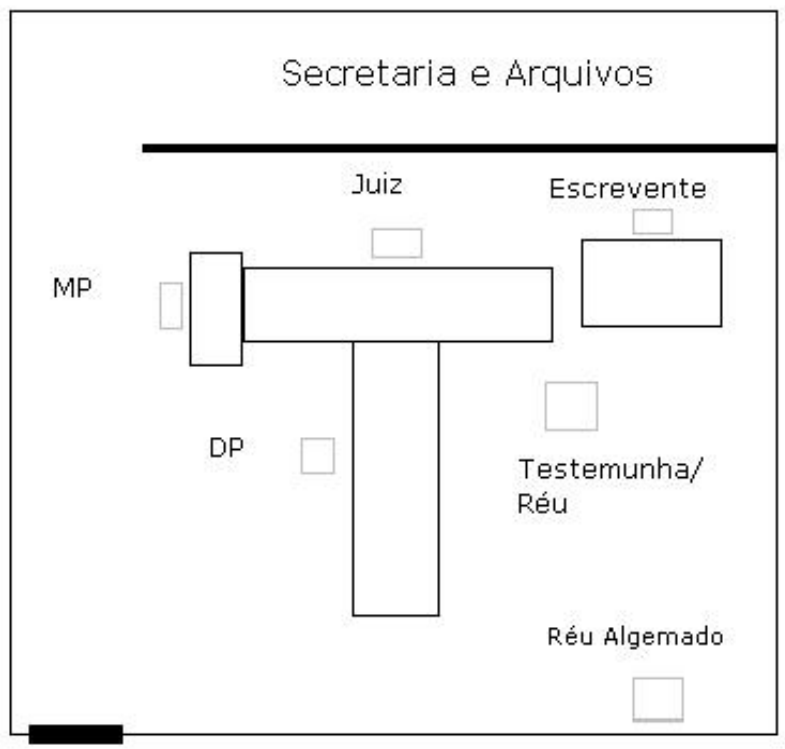

Fonte: Ribeiro, Cruz e Batitucci, 2004.

\footnotetext{
${ }^{13}$ Após seis meses da data do fato, há a decadência do direito, ou seja, o indivíduo não mais pode manifestar o seu desejo em processar o ofensor.
} 
Uma vez aceita pelo autor do fato e verificado que esse atende aos requisitos para a realização do acordo, o juiz homologa o que foi negociado entre o infrator e o representante do Ministério Público (MP) e aplica imediatamente uma pena não privativa de liberdade. No momento em que o autor do fato aceita a transação penal, o conciliador consulta o promotor, indagando a natureza da medida que o infrator deverá cumprir; via de regra, em Belo Horizonte, essa pena pode ser o pagamento de multa (pena pecuniária), prestação de serviços à comunidade ou a encaminhamento a Grupos Temáticos ${ }^{14}$.

Baseado em tipificações previamente estabelecidas, o promotor escolhe uma das medidas e estabelece os limites dessa, por exemplo, o número de dias da prestação de serviços à comunidade. Enquanto isso, nos corredores, os demais conciliadores especulam qual deveria ser a sentença, a partir de sua vivência no JECrim.

Com a proposta do MP em mãos, o conciliador volta à sala para dar ciência aos litigantes que, caso a aceitem, têm o direito a uma conversa rápida com defensor público - a lei estabelece que o aceite deve ser acompanhado de advogado e a maioria não possui meios para o pagamento de um particular.

Após a anuência (ou não) das partes em relação ao acordo, o conciliador seleciona, no computador, o formulário cabível para a situação e completa-o com os nomes dos envolvidos, a data do fato e, se for o caso, a duração da pena. $\mathrm{O}$ formulário é padronizado, de acordo com a natureza do delito - há um específico para direção sem habilitação, outro para lesão corporal, um distinto para vias de fato, etc. Após o visto de um coordenador, do juiz, do promotor e do defensor, o auxiliar da justiça entrega uma cópia do documento homologado pelas autoridades às partes e direciona o procedimento solucionado à sala do coordenador, seguindo para receber novos litigantes no salão de espera.

Com base nas observações realizadas, uma das principais constatações feitas foi a de que, similarmente à etapa da conciliação, os operadores são também pressionados a viabilizar uma enormidade de acordos entre o autor

\footnotetext{
${ }_{14}$ No ano de 2002, foi instituído o programa Central de Apoio e Acompanhamento às Penas e Medidas Alternativas, da Secretaria de Defesa Social de Minas Gerais, para fomento e coordenação da aplicação de penas alternativas, e também controle de seu cumprimento. A partir de 2007, o programa oferece uma nova modalidade de pena alternativa, os Grupos Temáticos, uma vez que, para determinados delitos, a prestação de serviços à comunidade não se mostrou adequada. Assim, os Grupos Temáticos buscam propiciar uma reflexão acerca dos comportamentos e provocar mudança, principalmente nos casos relacionados ao trânsito, violência contra a mulher e intra-familiar, o uso de drogas e os delitos ambientais. Os grupos funcionam em parceria com instituições parceiras do programa, que trabalham com os usuários as questões relativas às temáticas citadas. Até 2006, era também muito comum o recebimento, como pena, da obrigatoriedade de doação de cestas básicas a entidades carentes - o que foi expressamente proibido pela Lei 11340/2006, art. 17.
} 
da ação e o Ministério Público. Com isso, o auxiliar da justiça tende a influenciar a decisão da vítima de forma que ela exerça rapidamente o seu direito de representação e, assim, ele possa oferecer ao réu a proposta de transação penal dizendo o mínimo sobre os direitos e conseqüências dessa medida ao seu beneficiário.

Parte-se ainda do pressuposto de que o autor do delito possui ciência dos meandros acerca dos institutos do direito penal e, por isso, deve facilitar o trabalho do conciliador, que não deve despender tempo explicando em minúcias a consistência de uma figura jurídica como a transação penal. Em conseqüência, nem vítima nem réu sabem exatamente o que vai acontecer com eles ao final da querela, aceitando qualquer coisa que seja dita pela "autoridade" ou pelo "doutor".

Essa é uma das características que, acredita-se, mais diretamente contribui para a ocorrência daquilo que Kant de Lima (1997) chama de aplicação hierarquizada de princípios constitucionais igualitários no JECrim de Belo Horizonte. Um importante vetor no distanciamento da atividade cotidiana do JECrim de Belo Horizonte é a ausência de uma concepção institucional mais profissionalizada para o exercício da conciliação, o que poderia ser conseguido por meio de um treinamento efetivo, por exemplo. Note-se que no caso de uma estratégia como a do juizado especial criminal, a profissionalização adquire o significado não de acurácia técnica, mas de informalidade e oralidade, com vistas a se democratizar e publicizar o acesso à justiça, assim como sua dinâmica de funcionamento. Nesse sentido, poucos conciliadores, em geral os mais experientes, conduzem adequadamente o processo, informando a todas as partes envolvidas as conseqüências da aceitação da transação penal como mecanismo solucionador do litígio, além de empregar uma linguagem acessível.

A partir das observações realizadas no JECrim de Belo Horizonte, é possível afirmar que o procedimento realizado nessa arena é típico de uma linha de montagem, uma vez que a linguagem é padronizada tendo em vista os termos jurídicos utilizados, as decisões são formalizadas de acordo com o tipo de caso, os formulários estão sempre prontos aguardando apenas o nome dos envolvidos. Essa inversão de prioridades significa, na realidade, uma reaproximação do modo de trabalho desse com o vigente nas instâncias tradicionais do poder judiciário. A padronização, nessas instâncias, é reconhecida pelos juízes, os quais realizam encontros com os seus pares para delinear o padrão de operosidade, o tipo de sentença para determinados delitos e o modo que o fluxo processual deve ser estruturado no sentido de se ter menor dispêndio de recursos com maior produtividade (Sapori, 1995). 
Essa regularidade mecânica percebida na dinâmica de funcionamento das audiências do JECrim de Belo Horizonte é reafirmada pela existência de uma certa regularidade também no número de conciliações e sentenças. Os casos descritos assinalam a perspectiva de uma justiça formalizada, padronizada e outrossim distante da sistemática da Common Law. Por outro lado, a aproximação com o sistema da Civil Law se traduz menos em certeza jurídica e previsibilidade do direito, e mais na abundância de papéis e ritos a serem cumpridos; em uma institucionalidade refratária à linguagem popular e cheia de formalismos desnecessários à solução dos conflitos, mas indispensáveis ao processamento e punição do criminoso.

\section{Referências}

AZEVEDO, Rodrigo. O paradigma emergente em seu labirinto: notas para o aperfeiçoamento dos Juizados Especiais Criminais. In: WUNDERLICH, Alexandre; CARVALHO, Salo de (orgs.). Novos diálogos sobre os Juizados Especiais Criminais. Rio de Janeiro: Lumen Juris, 2005.

Juizados Especiais Criminais: uma abordagem sociológica sobre a informalização da justiça penal no Brasil. In: Revista Brasileira de Ciências Sociais, São Paulo, v. 17, n. 47, out. 2001.

AZEVEDO, Rodrigo Ghiringhelli; AZEVEDO, Tupinambá Pinto de. Política criminal e direito penal: histórico e tendências contemporâneas. In: KANT DE LIMA et al. (orgs.). Reflexões sobre a segurança pública e justiça criminal numa perspectiva comparada. Brasília: Secretaria Especial dos Direitos Humanos, 2008.

BATITUCCI, Eduardo Cerqueira. Elementos para uma Sociologia Histórica da Polícia Civil em Minas Gerais. Congresso da Sociedade Brasileira de Sociologia, XIII., Recife-PE, 2006. Disponível em: <www.sbsociologia.com.br>. BATITUCCI, Eduardo; CRUZ, Marcus Vinícius; SILVA, Breno Inácio. Fluxo do crime de homicídio no Sistema de Justiça Criminal de Minas Gerais. ENCONTRO DA ANPOCS, 30., Caxambu, 2006.

BRAITHWAITE, John. Entre a proporcionalidade e a impunidade: confrontação - verdade - prevenção. In: SLAKMON, Catherine; MACHADO, Maíra Rocha; BOTTINI, Pierpaolo Cruz (orgs.). Novas direções na governança da justiça e da segurança. Brasília-DF: Ministério da Justiça, 2006.

CHIES, Luiz Antônio Bogo. Em busca do conflito perdido... esgarçamentos daltônicos para uma justiça recriadora e as armadilhas da Lei Maria da Penha. In: KANT DE LIMA et al. (orgs.). Reflexões sobre a segurança pública e justiça criminal numa perspectiva comparada. Brasília: Secretaria Especial dos Direitos Humanos, 2008.

CUNHA, Luciana Gross Siqueira. Juizado Especial: ampliação do acesso à Justiça? In: SADEK, Maria Tereza. Acesso à Justiça. São Paulo: Fundação Konrad Adenauer, 2001.

GILISSEN, John. Introdução Histórica ao Direito. Lisboa: Fundação Calouste Gulbenkian, 1998. 
KANT DE LIMA, Roberto. Polícia e exclusão na cultura judiciária. In: Tempo Social - Revista de Sociologia da Universidade de São Paulo, v. 1, n. 9, p. 169-183, maio 1997.

Carnavais, malandros e heróis: o dilema brasileiro do espaço público. In: GOMES, Laura Graziela; BARBOSA, Lívia; DRUMOND, José Augusto. O Brasil não é para principiantes: carnavais, malandros e heróis 20 anos depois. Rio de Janeiro: FGV, 2000.

KANT DE LIMA, Roberto; AMORIM, Maria Stella; BURGOS, Marcelo. A violência doméstica nos Juizados Especiais Criminais brasileiros: desafios para o direito e para os tribunais brasileiros. Niterói, 2004. (mimeo).

PAIXÃO, Antônio Luis. Notas sobre a organização policial numa área metropolitana. Dados, v 25, 1982.

PINHEIRO et al. Continuidade autoritária e construção da democracia. São Paulo: NEV/USP, 1999.

RIBEIRO, Ludmila; CRUZ, Marcus Vinícius; BATITUCCI, Eduardo. Morosidade necessária ou impunidade? O tempo dos tribunais do júri em Minas Gerais. Congresso da Sociedade Brasileira de Sociologia, XIV., Rio de Janeiro, 2009.

Liberdade tutelada: a normatização e a burocratização da transação penal nos Juizados Especiais Criminais: estudo de caso em Belo Horizonte - Minas Gerais. Encontro Anual da ANPOCS, 28., Caxambu-MG, 2004. Disponível em: $<$ www.anpocs.org.br>.

SAlguEIRO, Alexandre Douglas. A Polícia Civil e a Lei 9.099/95. Monografia (Curso de Especialização em Segurança Pública) - Fundação João Pinheiro, Belo Horizonte, 2001.

SAPORI, Luís Flávio. A administração da Justiça Criminal numa área metropolitana. In: Revista Brasileira de Ciências Sociais, n. 29, p. 143-156, out. 1995.

SANTOS, Andréia dos; BATITUCCI, Eduardo Cerqueira. Fábrica de Carimbos: mediação de conflito e papel do judiciário no JECrim - Belo Horizonte/MG. Reunião Brasileira de Antropologia, 26., Porto Seguro-BA, 2008.

VARGAS et al. Metodologia de tratamento do tempo da morosidade processual na Justiça Criminal. Brasília: Ministério da Justiça, 2005.

VON HIRSCH, Andrew; ROBERTS, Julian; BOTTOMS, Anthony; ROACH, Kent Roach; SCHIFF, Mara (Eds.). Restorative Justice and Criminal Justice. Oxford: Hart Publishing, 2003. 